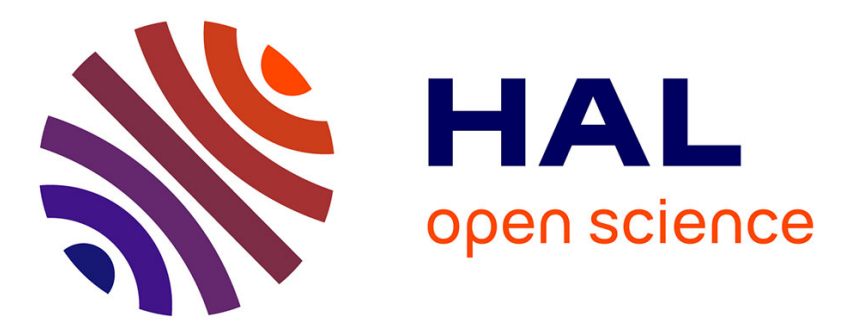

\title{
Internet Traffic Management Under EU Regulation 2015/2120 - The Need for the Co-operation of Legal and Computer Scientists
}

Andrzej Nalęcz

\section{- To cite this version:}

Andrzej Nalęcz. Internet Traffic Management Under EU Regulation 2015/2120 - The Need for the Co-operation of Legal and Computer Scientists. Proceedings of 39th International Conference on Information Systems Architecture and Technology - ISAT 2018, Wroclaw University of Science and Technology, Sep 2018, Nysa, Poland. pp.90 - 99, 10.1007/978-3-319-99981-4_9 . hal-01871831

\section{HAL Id: hal-01871831 \\ https://hal.science/hal-01871831}

Submitted on 14 Sep 2018

HAL is a multi-disciplinary open access archive for the deposit and dissemination of scientific research documents, whether they are published or not. The documents may come from teaching and research institutions in France or abroad, or from public or private research centers.
L'archive ouverte pluridisciplinaire $\mathbf{H A L}$, est destinée au dépôt et à la diffusion de documents scientifiques de niveau recherche, publiés ou non, émanant des établissements d'enseignement et de recherche français ou étrangers, des laboratoires publics ou privés.

$$
\text { Copyright }
$$


This is a pre-copyedited version of a contribution published in Information Systems Architecture and Technology: Proceedings of 39th International Conference on Information Systems Architecture and Technology - ISAT 2018, L. Borzemski, J. Świątek, Z. Wilimowska (eds.) published by Springer, 2018, pp. 9099. The definitive authenticated version is available online via https://doi.org/10.1007/978-3-319-99981-4_9

\title{
Internet Traffic Management under EU Regulation 2015/2120 - the Need for the Co-operation of Legal and Computer Scientists
}

\author{
Andrzej Nałęcz ${ }^{1}$ \\ ${ }^{1}$ Faculty of Management, Warsaw University, Szturmowa 1/3, 02-678 Warsaw, Poland \\ ANalecz@wz.uw.edu.pl
}

\begin{abstract}
EU Regulation 2015/2120 introduces a network neutrality regime into European electronic communications law. The application and enforcement of the abstract rules established by the regulation influences all the stakeholders in the internet value chain. The regulation's provisions are ambiguous and inconclusive. Legal and computer scientists must co-operate to provide an interpretation of those provisions that would, first, respect the rights of the end-users of internet access services and provide a user experience in line with the regulation, and second, respect the technical realities of managing traffic on the internet. The paper presents the legal framework of traffic management under the regulation and exposes problems which may only be resolved by a synthesis of the legal and computer science approaches. These include: the classification of traffic management measures into basic, reasonable and exceptional categories, recognized by the regulation; the admissibility of traffic classification; the definition of congestion befitting the regulation; the role of traffic management measures in congestion control. If these issues are not resolved, the exercise of the rights of endusers of internet access services may be limited, and the providers of these services may be subjected by national regulatory authorities to unreasonable obligations.
\end{abstract}

Keywords: Basic Traffic Management Measures, Reasonable Traffic Management Measures, Exceptional Traffic Management Measures, Internet Congestion, Classes of Traffic.

\section{Introduction}

Internet traffic management was not traditionally regulated by EU law. However, that changed with the entering into force of the Regulation 2015/2120 of the European Parliament and of the Council of 25 November 2015 laying down measures concerning open internet access and amending Directive 2002/22/EC on universal service and users' rights relating to electronic communications networks and services and Regulation (EU) No 531/2012 on roaming on public mobile communications networks within the Union (further referred to as Regulation 2015/2120). The regulation introduced a network neutrality regime into EU electronic communications law, establishing the rights 
of end-users of internet access services and requiring the providers of those services to manage internet traffic respecting the rules set by the law.

The purpose of this article, written by a legal scientist, is to determine which problems related to internet traffic management have been solved by the law and which should be solved by computer scientists. While due to the principle of technology neutrality [1] the Regulation 2015/2120 does not specify any concrete technical standards and relies solely on abstract rules, in the end it is applied in the real world, where suppliers of network devices and providers of internet access services face the problem of providing and utilizing solutions that are both effective and not illegal under the Regulation 2015/2120. Legal scientist and computer scientists should come together to make clear what these solutions should be.

\section{The Terminology of the Regulation $2015 / 2120$}

\subsection{Internet Access Services and Specialized Services}

Article 2 of the Regulation 2015/2120 defines internet access services as publicly available electronic communications services that provide access to the internet, and thereby connectivity to virtually all end points of the internet, irrespective of the network technology and terminal equipment used. From the point of view of analyzing traffic management measures, the most important conclusion arising from the interpretation of the cited provision is the fact that the Regulation $2015 / 2120$ pertains only to publicly available electronic communications services - that is those that are offered to the public, either on the consumer or business markets, or on both, rather than only to a select group of end-users. Thus, traffic management in private networks is not subject to the requirements of the Regulation 2015/2120 and is not mentioned or discussed further in the paper.

Article 3 (5) of the Regulation 2015/2120 allows providers of internet access services and providers of content to offer services other than internet access services which are optimized for specific content, applications or services, or a combination thereof, where the optimization is necessary in order to meet the requirements for a specific level of quality. These are the so-called specialized services. Unlike internet access services, they come with Quality of Service guarantees. The distinction is important inasmuch that it shows that while traffic management of internet traffic may involve traffic classification and different treatment of the various classes of traffic (which is discussed below), it may only distinguish between classes of best-effort traffic types, since QoS optimization is limited to specialized services.

\subsection{The Lack of a Legal Definition of "Traffic Management" in the Regulation 2015/2120}

The Regulation 2015/2120 does not define the term "traffic management". However, traffic management was discussed in the debate leading up to the regulation being legislated. The Body of European Regulators for Electronic Communications (BEREC), which was tasked by the European Commission with investigating issues related to network neutrality and coordinated the discussion and presently coordinates the 
regulation's enforcement, leans towards a very broad understanding of traffic management, describing it as "the way the traffic is forwarded in the networks (...), which may include both regular first-come-first-serve management of traffic and more advanced ways of shuffling traffic through the networks" [2].

Such a broad understanding of traffic management differs from the one presented in computer science literature. In [3], Constantine and Krishnan describe the traffic management capabilities of network devices as those pertaining to: traffic classification, traffic policing, traffic scheduling, traffic shaping and active queue management. This approach, then, excludes the simplest technical solutions, such as passive queue management, from the scope of the term "traffic management".

The broad approach to traffic management in interpreting the Regulation 2015/2120 is necessitated by the requirements of network neutrality and by the need to safeguard the rights of end-users - as shaped by the regulation. Only a broad approach may prevent the providers of internet access services from circumventing the network neutrality rules by claiming a practice they are engaging in does not in fact constitute traffic management subject to the Regulation 2015/2120. Thus, traffic management under the Regulation 2015/2120 should be understood to include all the technical solutions, be it simple or complex, used to measure, analyze, classify and forward traffic in the network.

\section{Traffic Management Measures under the Regulation 2015/2120}

\subsection{Primal and Dual Congestion Control Under the Regulation 2015/2120}

One of the objectives of utilizing traffic management measures under the Regulation 2015/2120 is congestion control. In the networking literature [4], "primal congestion control refers to the algorithms executed by the traffic sources for controlling their sending rates or window sizes. (...) TCP algorithms fall in this category. Dual congestion control is implemented by the routers through gathering information about the traffic traversing them. A dual congestion algorithm updates, implicitly or explicitly, a congestion measure or congestion rate and sends it back, implicitly or explicitly, to the traffic sources that use that link." While the Regulation 2015/2120 itself does not mention these two types of congestion control, they are referenced by BEREC and in the legal literature as "end-point based" and "network-internal" congestion control $[5,6]$. The former does not contravene the provisions of the Regulation 2015/2120 on traffic management [5] and is in fact outside their scope [6]. Thus, the regulation applies only to the latter, network-internal measures.

\subsection{Classification of Traffic Management Measures under the Regulation 2015/2120}

The Regulation 2015/2120 implies the existence of basic traffic management measures, and explicitly mentions two other types of measures - reasonable traffic management measures, regulated by Article 3 (3) second subparagraph of the regulation, and those going beyond the reasonable, regulated by Article 3 (3) third subparagraph. The latter 
are called exceptional traffic management measures by BEREC and in the legal literature $[5,6]$. Basic measures are the simplest ones and do not involve any traffic classification. Reasonable measures may rely on traffic classification and may involve different treatment of specific categories of best-effort traffic. Exceptional measures may be employed only under exact circumstances, enumerated in the Regulation 2015/2120, and they may go as far as traffic blocking. All types of measures are described in further detail below.

\subsection{Basic Traffic Management measures}

Article 3 (3) first subparagraph of the Regulation states that Providers of internet access services shall treat all traffic equally, when providing internet access services, without discrimination, restriction or interference, and irrespective of the sender and receiver, the content accessed or distributed, the applications or services used or provided, or the terminal equipment used. The cited provision implies the recognition of a type of traffic management measures, unnamed in the regulation, and known in the legal literature as basic traffic management measures [6]. The key phrase in the provision is that all traffic should be treated equally. Since only reasonable and exceptional traffic management measures allow traffic classification and the differentiated treatment of specific classes of traffic, the equal treatment of traffic in this context must be understood in its most narrow, linguistic meaning. Thus, basic traffic management measures must entail the identical treatment of every data packet traversing the network. As has been explained in the legal literature, they involve a transmission of data packets without any interference and completely independent of the class of traffic they belong to, and are therefore completely neutral from the point of view of the end-users [6].

Handling traffic using Passive Queue Management (PQM), involving first-in-firstout and tail drop algorithms, and giving all data packets the same priority undoubtedly constitutes basic traffic management measures. However, the status of classless Active Queue Management (AQM) as either a basic or reasonable traffic management measure is unclear under the Regulation 2015/2120. BEREC seems to indicate that all AQM (be it class-based or classless) should be assessed under the requirements for reasonable rather than basic measures [5]. This is unconvincing. As will be explained below, reasonable traffic management measures rely on traffic classification. Since classless AQM, such as Random Early Detection (RED) do not distinguish between traffic classes, they should be considered basic traffic management measures. RED with In and Out (RIO) and Weighted RED (WRED) algorithms allow a differentiated treatment of packets and therefore should be considered reasonable traffic management measures under the Regulation 2015/2120 (described in the following section), rather than basic ones. This is one of the areas where the application and enforcement of the Regulation $2015 / 2120$ would greatly benefit from the input of computer scientists.

\subsection{Reasonable Traffic Management Measures}

Requirements for Reasonable Traffic Management - Introduction. Article 3 (3) second subparagraph of the Regulation 2015/2120 introduces the concept of reasonable 
traffic management measures and sets out the requirements which must be met by a measure for it to be considered reasonable. Under the cited provision, such measures must be transparent, non-discriminatory and proportionate, and must not be based on commercial considerations but on objectively different technical quality of service parameters of the specific categories of traffic. They must not monitor the specific content and must not be maintained for longer than necessary. Article 3 (3) third subparagraph, which generally pertains to exceptional traffic management measures, also exemplifies what kinds of the treatment of traffic may not be considered reasonable. All these requirements are discussed in detail below.

Transparency. The transparency of a traffic management measure pertains to its disclosure to both the end-users and the national regulatory authorities. While the endusers must only very broadly be informed of traffic management measures by means of the contract including internet access services, the information provided to the national regulatory authority must be detailed enough for the regulator to be able to determine whether a given measure satisfies the requirement of reasonableness.

Non-discrimination. Traffic classes. Reasonable traffic management measures must be non-discriminatory. Non-discrimination is a well-known concept in EU law. It "is not equivalent to the distinction as such but refers to the disadvantageous treatment of an individual based on a ground prohibited by law [and] it occurs when comparable situations are treated differently and different situations are treated in the same way", when it is not objectively justified [7]. In the case of internet traffic management, the requirement of non-discrimination pertains not to individuals but rather to data packets transferred over the internet. All packets must be transmitted according to the same rules, e.g. using the first-in-first-out algorithm, unless there is an objective justification for differentiation. The Regulation 2015/2120 unequivocally states in Article 3 (3) second subparagraph that specific categories of traffic may be treated differently based on their objectively different quality of service requirements (the regulation uses the term "traffic categories" rather than "traffic classes", used in computer science). This harmonizes with the objective of reasonable traffic management, described in recital 9 of the Regulation 2015/2120 as contributing to an efficient use of network resources and to an optimization of overall transmission quality. Treating all data packets in the same way regardless of the circumstances, especially when network congestion occurs, would lead to an inefficient allocation of network resources, such as capacity, and it would also adversely affect the user experience. Thus, the key issues of interest to both legal and computer scientists are: establishing classes of traffic with objectively different quality of service requirements, identifying data flows as belonging to a specific class of traffic (traffic classification), and specifying the circumstances under which the treatment of the various classes of traffic should be differentiated. The Regulation 2015/2120 does not specify which network devices may be involved in classifying traffic flows as belonging to specific categories of traffic - it may therefore occur in any device, e.g. in routers or in specialized middleboxes.

Proportionality. Reasonable traffic management measures must also be proportionate. Proportionality is a well established general principle of EU law. It "requires that there be a reasonable relationship between a particular objective to be achieved and the means used to achieve that objective" [8]. When an action is undertaken that is subject to a 
proportionality review, a test may be carried out to evaluate whether the action satisfies several specific requirements: the pursuit by that action of legitimate aims; the suitability of the means, referring to its ability to further the achievement of the objective; the necessity of the means, that is whether it affects the rights of individuals as little as possible; and finally, proportionality in the narrow sense, that is the weighing of the reduction of the enjoyment of rights against the level of realization of the objective [8]. A traffic management measure may be considered reasonable only when it passes the test - that is when it cumulatively satisfies all its four criteria, described below in further detail.

Legitimate aim. A traffic management measure pursues a legitimate aim when it is not based on commercial considerations (which is discussed below) but seeks to achieve an efficient use of network resources and contributes to the user experience, while not infringing on the rights of the end-users enshrined in the Regulation 2015/2120. E.g. a measure giving precedence to traffic generated by a specific application (rather than to a class of traffic generated by all the applications sharing similar quality of service requirements) would not be considered as pursuing a legitimate aim, even if it contributed to the efficient use of network resources, since it would discriminate between specific applications, which the regulation forbids to protect the end-users' rights.

Suitability. A measure is suitable when it indeed effectively serves the purpose for which it was introduced. E.g. if the purpose of employing a specific measure is the control of congestion, it will be considered suitable only if it can be proved that it in fact contributes to limiting congestion.

Necessity. A measure is necessary when the aim it pursues is not achievable by using another measure, which would influence the right of the end-user to access any internet content to a lesser extent. E.g. if the efficient use of network resources and a satisfying user experience may not be achieved by using classless traffic management measures, solutions distinguishing between several classes of best-effort traffic types may be utilized.

Proportionality in the narrow sense. Finally, a traffic management measure is proportionate in the narrow sense when its introduction does not adversely affect the enduser's rights to an excessive extent, e.g. a measure introduced to provide efficient access to one category of internet content (translating into a specific class of traffic) may not lead to another category of content becoming effectively unusable by the end-user.

Commercial Considerations. Reasonable traffic management measures may not be based on commercial considerations. This means that a provider of internet access services may not make using or refraining from the use of specific traffic management measures conditional upon receiving monetary or non-monetary remuneration from any party, be it an internet content provider, an end-user, or anybody else.

Monitoring specific content. Under Article 3 (3) second subparagraph of the Regulation 2015/2120, reasonable traffic management measures may "not monitor the specific content". This is understood by BEREC as a prohibition on monitoring the specific content of a data packet, i.e. the transport layer protocol payload [5]. On the other hand, the information contained in the IP packet header or transport layer protocol header is considered by BEREC as generic rather than specific content and therefore reasonable traffic management measures may rely on it [5]. This includes such common 
identification methods as those based on the connection's port numbers [9]. In practice, the prohibition on monitoring specific content means that reasonable traffic management may not under any circumstances involve deep packet inspection techniques (DPI). This may prove problematic in practice, as such solutions are often used in middleboxes [10]. However, the interpretation of the Regulation 2015/2120 does not preclude the use of machine learning solutions, if they do not rely on DPI. Thus, the utilization of pattern recognition algorithms described in [9] is allowed.

How Long Reasonable Traffic Management Measures May be Maintained? The Congestion Control Controversy. Under the Regulation 2015/2120, reasonable traffic management measures may not be maintained for longer than necessary, which relates to the proportionality principle. Both BEREC [5] and legal scientists [6] distinguish between trigger functions and employing traffic management measures as such. A trigger function may be "implemented and in place (...) on an ongoing basis inasmuch as the traffic management measure only becomes effective in times of necessity" [5]. Thus, employing a measure which continuously or regularly affects traffic is questionable from the point of view of the requirement of necessity $[5,6]$.

Technical solutions involving class-based AQM algorithms that trigger specific treatment of data packets to control congestion, but which allow for first-in-first-out, class-less functionality when there is no congestion seem to be in line with the Regulation 2015/2120 and fall within the category of reasonable traffic management measures. However, this sensible conclusion is weakened to the extent of being muddled by BEREC's stance and the imprecise wording of the regulation. BEREC indicates that class-based measures preventing "impending congestion" constitute exceptional traffic management measures and are subject to the limitations of Article 3 (3) subparagraph three rather than subparagraph two [5]. If that interpretation were to be accepted, then there would appear to be no circumstances under which any reasonable traffic management measures could ever be used. Why else reasonably manage traffic than to prevent and mitigate congestion, if class-based differentiation based on commercial considerations is banned altogether? Computer scientists' input on the issue would be invaluable.

What treatment of traffic may not be considered reasonable. Article 3 (3) third subparagraph of the Regulation 2015/2120 exemplifies what may not be involved in reasonable traffic management. The actions mentioned include, but are not limited to: blocking, slowing down, altering, restricting, interfering with, degrading or discriminating between specific content, applications or services, or specific categories thereof. Such actions are limited to exceptional traffic management measures, as described by BEREC [5] and in the legal literature [6]. The interpretation of the cited provision is problematic, especially with respect to the slowing-down of traffic. Best-effort, classbased AQM involves priority schemes for data packets, effectively slowing some packets down in relation to others. This should be considered as belonging to reasonable traffic management measures (as long as traffic classes are based on objective and genuine QoS requirements), rather than exceptional ones, as the Regulation implies. Computer scientists' elaboration on the issue would be greatly appreciated. 


\subsection{Exceptional Traffic Management Measures}

Exceptional Traffic Management Measures - Introduction. Under Article 3 (3) third subparagraph of the Regulation 2015/2120, in certain, very specific circumstances, enumerated in the regulation and discussed below, traffic management measures going beyond those deemed reasonable may be used. In the literature and BEREC documents, these measures are called exceptional traffic management measures [5, 6]. Even though it is not clearly stated in the Regulation 2015/2120, a legal interpretation of the provisions leads to the conclusion that these measures - just like the reasonable ones - must be transparent and proportional, may not be based on commercial considerations and may not be maintained for longer than necessary. Unlike reasonable measures, however, the exceptional ones may under some circumstances monitor the specific content. They may also involve the actions mentioned in the previous paragraph above, including the blocking of traffic.

Circumstances under Which Exceptional Traffic Management Measures May be Used. The circumstances under which exceptional traffic management measures may be used have been enumerated in Article 3 (3) (a)-(c) of the Regulation 2015/2120 and are discussed below.

Compliance with Legislation. Under Article 3 (3) (a) of the Regulation 2015/2120, exceptional traffic management measures may be employed to ensure compliance with EU or national legislation, and with acts that comply with that legislation, e.g. decisions by courts or other public authorities. This involves inter alia the blocking of illegal content, such as child pornography under national laws resulting from the transposition of Article 25 of the Directive 2011/92/EU of the European Parliament and of the Council of 13 December 2011 on combating the sexual abuse and sexual exploitation of children and child pornography, and replacing Council Framework Decision 2004/68/JHA. The relevant legislation usually determines what specific traffic management measures should be employed to enact it, e.g. Domain Name Service blocking. $\mathrm{EU}$ and national legislators would be advised to cooperate with computer scientists in choosing the most appropriate, specific measures to be used.

Preservation of network integrity and security. Under Article 3 (3) (b) of the Regulation $2015 / 2120$, exceptional traffic management measures may be employed to preserve the integrity and security of the network, of the services provided via that network, and of the terminal equipment of end-users. This is rather uncontroversial and has been convincingly explained by BEREC in [5].

Preventing and Mitigating Congestion. Under Article 3 (3) (c) of the Regulation $2015 / 2120$, exceptional traffic management measures may be employed to "prevent impending network congestion and to mitigate the effects of exceptional or temporary network congestion, provided that equivalent categories of traffic are treated equally". The cited provision is problematic for two reasons: first, the Regulation 2015/2120 does not define network congestion, and second, it does not contain provisions that would sufficiently differentiate between cases when reasonable or exceptional traffic management measures should be employed to control congestion.

Understanding what the term "congestion" used in the Regulation 2015/2120 is supposed to mean is not as straightforward as it may seem. In networking literature 
congestion is "defined as a state or condition that occurs when network resources are overloaded, resulting in impairments for network users as objectively measured by the probability of loss and/or delay" [4]. However, other definitions of congestion are also presented in the literature [11]. Legal and computer scientists should work together to provide a definition of congestion best suited to the application and enforcement of the Regulation 2015/2120.

Taken literally, Article 3 (3) (c) of the Regulation 2015/2120 implies that any "impending network congestion" justifies the use of exceptional traffic management measures. Such an interpretation however is unacceptable. As has been mentioned above, under the Regulation 2015/2120 solutions implemented in the network to aid in congestion control, such as Active Queue Management, generally fall into the category of reasonable traffic management. The use of exceptional rather than reasonable traffic management measures in order to control impending congestion is certainly justified in cases when a congestion collapse of the network is predicted based on the analysis of the network traffic. Other cases should be elaborated upon by computer scientists, considering both the need to safeguard the end-users' rights enshrined in the Regulation 2015/2120, and the technical realities of network traffic management.

\section{Conclusions}

Since the Regulation 2015/2120 came into force, all traffic management measures used by providers of internet access services in the EU must meet the requirements introduced by its provisions. Thus, the law has become one of the factors that have to be considered when designing and applying internet traffic management measures employed in networks used to provide publicly available internet access services in Europe. The proper interpretation of the Regulation 2015/2120, serving its sensible application and enforcement, necessitates the co-operation of legal and computer scientists. The former may not disregard the technical realities of managing internet traffic, which should be elaborated on by the latter, in turn taking legal considerations into account.

Computer scientists' input would be invaluable in clearing up the many ambiguities created by the Regulation 2015/2120 with respect to the various types of traffic management measures categorized by it, namely the basic, reasonable and exceptional ones. The distinction between these three categories of measures is of the utmost importance to the application of the Regulation 2015/2120, and yet it was not made clear enough by the legislators or BEREC. Computer scientists undoubtedly may help in determining which concrete, technical solutions or types thereof fall within each of the three categories. Specifically, even though the need to control congestion in the network is apparently one of the main reasons of introducing any traffic management measures, the Regulation 2015/2120 is unclear on when reasonable or exceptional measures may be used to control congestion. Computer scientists' input in resolving this conundrum, as well as interpreting how the term "congestion" should be understood for the purpose of applying and enforcing the regulation would be appreciated.

Computer scientists may also greatly assist in resolving the issues related to the treatment of various classes of traffic. The Regulation 2015/2120 allows the objectively 
justified differentiation in the treatment of traffic classes, based on their different technical quality of service requirements. Computer scientists may delineate classes of traffic with objectively different quality of service requirements, determine the means of identifying data flows as belonging to a specific class of traffic (traffic classification), and specify the circumstances under which the treatment of the various classes of traffic should be differentiated.

\section{References}

1. Maxwell, W.J., Bourreau, M.: Technology Neutrality in Internet, Telecoms and Data Protection Regulation. Computer and Telecommunications Law Review 21(1), 1-4 (2015). https://www.hoganlovells.com/ /media/hogan-lovells/pdf/publication/201521ctlrissue1maxwell_pdf.pdf

2. BEREC Homepage, https://berec.europa.eu/eng/netneutrality/traffic_management/, last accessed 2018/05/13.

3. Constantine, B., Krishnan, R.: Traffic Management Benchmarking. RFC 7640. https://tools.ietf.org/html/rfc7640 (2015).

4. Papadimitrou, D., Welzl, M., Scharf, M., Briscoe, B.: Open Research Issues in Internet Congestion Control. RFC 6077. https://tools.ietf.org/html/rfc6077 (2011).

5. BEREC: BEREC Guidelines on the Implementation by National Regulators of European Net Neutrality Rules. BoR (16) 127. https://berec.europa.eu/eng/document_register/subject_matter/berec/download/0/6160-berec-guidelines-on-the-implementation-b_0.pdf.

6. Piątek, S.: Rozporządzenie UE Nr 2015/2120 w zakresie dostępu do otwartego internetu. 1st edn. Wydawnictwo CH Beck, Warszawa (2017). [publication in Polish]

7. Maliszewska-Nienartowicz, J.: Direct and Indirect Discrimination in European Union Law - How to Draw a Dividing Line? International Journal of Social Sciences III(1), 41-55 (2014). http://www.iises.net/download/Soubory/soubory-puvodni/pp041055_ijoss_2014v3n1.pdf.

8. Klatt, M., Meister, M.: The Constitutional Structure of Proportionality. $1^{\text {st }}$ edn. Oxford University Press, Oxford (2012).

9. Dainotti, A., Pescapé, A., Claffy, K. C.: Issues and Future Directions in Traffic Classification. IEEE Network 26(1), 35-40 (2012). doi: 10.1109/MNET.2012.6135854.

10. Bremler-Barr, A., Harchol, Y., Hay, D., Koral, Y.: Deep Packet Inspection as a Service. In: CoNEXT ' 14 Proceedings of the $10^{\text {th }}$ ACM International Conference on emerging Networking Experiments and Technologies, pp. 271-282. ACM, New York (2014). doi: 10.1145/2674005.2674984.

11. Bauer, S., Clark, D., Lehr, W.: The Evolution of Internet Congestion. https://groups.csail.mit.edu/ana/Publications/The_Evolution_of_Internet_Congestion_Bauer_Clark_Lehr_TPRC_2009.pdf (2009). 